\title{
Evaluasi Kinerja Simpang Bersinyal Jalan Pahlawan - Raden Saleh Sarif Bustaman di Bogor Jawa Barat
}

\author{
(Performance Evaluation of Signaled Intersection of Pahlawan Street and Raden \\ Saleh Sarif Bustaman Street in Bogor West Java)
}

\footnotetext{
Dwi Bangkit Prakoso ${ }^{1}$, Sutoyo ${ }^{*}$, dan Tri Sudibyo ${ }^{1}$

${ }^{1}$ Departemen Teknik Sipil dan Lingkungan, Fakultas Teknologi Pertanian, Institut Pertanian Bogor. Jl. Raya Dramaga, Kampus IPB Dramaga, PO BOX 220, Bogor, Jawa Barat Indonesia

*Penulis korespondensi: sutoyo@apps.ipb.ac.id
}

Diterima: 05 Maret 2019

Disetujui: 21 Maret 2019

\begin{abstract}
Signaled intersection of Pahlawan steet and Raden Saleh Sarif Bustaman street is one of the main streets in Bogor. This intersection has 3-arm approaches namely Pahlawan Street at East, Raden Saleh Sarif Bustaman Street at North, and Empang Street at West. Highest traffic on weekend is 11653 units/hour or 5087 SMP/hour which occur between 5.20-7.20 pm. Pahlawan - Raden Saleh Sarif Bustaman street obtained inconsistent time cycle of APILL and size of approach dimension which resulted in intersection with high saturated degree. The saturation degree of the intersection of the eastern approaches was 0.75 which meant that this value was same with the standard value in MKJI 1997 which is 0.75. This meant that the performance of intersection capacity was already saturated. The high saturation degree of the intersection resulted in a low level of service level and was classified as, service level $E$ with the intersection delay 45 seconds/SMP. Scenario II is the best alternative scenario for intersections, with the addition of road or lane widening, so the intersection capacity of the eastern, northern and western approaches were 3931, 5066 and 4562 SMP/hour respectively. The average intersection delay became to 9 seconds / SMP, and classified as service level B.
\end{abstract}

Key words: capacity, intersection, intersection delay, service level

\section{PENDAHULUAN}

Padatnya penduduk di wilayah Bogor merupakan salah satu faktor yang menyebabkan terjadinya permasalahan lalu lintas. Selain itu, pertumbuhan kendaraan pribadi yang cukup tinggi juga akumulasi pelayanan angkutan umum di dalam wilayah Bogor menjadi faktor permasalahan lalu lintas yang terjadi (DLLAJ Kota Bogor). Salah satu titik permasalahan lalu lintas (kemacetan) yang terjadi di Kota Bogor yaitu pada Simpang bersinyal Jalan Pahlawan - Raden Saleh Sarif Bustaman atau simpang Empang. Arus lalu lintas Kota Bogor pada jam kerja meningkat tajam dibandingkan waktu lainnya. Tingginya arus lalu lintas pada jam puncak memerlukan penanganan lalu lintas yang baik, peningkatan intensitas lalu lintas dapat mengakibatkan simpang jalan tidak lagi mampu memberikan layanan yang baik melalui alat pemberi isyarat lalu lintas (APILL). Pemberian sinyal lalu lintas menggunakan APILL merupakan metode paling efektif untuk mengantisipasi kepadatan lalu lintas pada simpang (Galfi 2012).

Antrian pada jaringan simpang bersinyal terjadi akibat durasi rata-rata antrian kendaraan melebihi waktu hijau (sinyal jalan), bahkan dapat mencapai seluruh panjang lengan pendekat (Puspita 2010). Hambatan pada simpang bersinyal antara lain waktu tunggu yang lama pada kondisi arus puncak, sehingga 
meningkatkan panjang antrian kendaraan pada lengan simpang. Perilaku pengguna jalan seperti menunggu penumpang yang mengurangi kecepatan kendaraan pada lengan simpang juga mengakibatkan panjangnya antrian pada simpang. Kemacetan yang terjadi pada persimpangan merupakan indikasi jenuhnya kapasitas simpang pada kondisi arus puncak.

Simpang Jalan Pahlawan - Raden Saleh Sarif Bustaman merupakan simpang yang menghubungkan kecamatan Bogor Selatan dan Bogor Tengah. Simpang ini dilewati kendaraan dari Jalan Pahlawan (arah Bogor Nirwana Residence), Jalan Raden Saleh Bustaman (arah Bogor Trade Mall) dan Jalan Empang. Tingkat mobilitas yang melintasi Simpang Jalan Pahlawan - Raden Saleh Sarif Bustaman ini cukup tinggi, sehingga diperlukan sarana dan prasarana jalan yang memadai agar arus lalu lintas berjalan lancar. Namun kenyataannya pada Simpang Jalan Pahlawan - Raden Saleh Sarif Bustaman sering terjadi kemacetan. Hal ini menunjukkan bahwa sarana prasarana jalan saat ini tidak mampu mengimbangi beban jumlah kendaraan yang ada. Melihat pentingnya simpang ini sebagai akses arus lalu lintas, maka dirasa perlu adanya evaluasi guna menilai kinerja simpang Jalan Pahlawan - Raden Saleh Sarif Bustaman sehingga dapat memberikan tindak lanjut penanganan apabila diperlukan. Evaluasi kinerja simpang dilakukan berdasarkan metode yang ada pada manual kapasitas jalan Indonesia (MKJI). Manual ini berfungsi sebagai pedoman perhitungan kapasitas dan perilaku lalu lintas di segmen jalan dan jaringan jalan (Dirbinkot 1997). Berdasarkan pertimbangan tersebut, maka ditentukan bahwa parameter yang digunakan untuk menilai kinerja simpang tak bersinyal ini mencakup kapasitas, derajat kejenuhan, tundaan dan peluang antrian.

\section{METODOLOGI}

Penelitian ini diawali dengan studi literatur mengenai kajian evalusi kinerja simpang bersinyal yang meliputi karakteristik permasalahan pada simpang bersinyal, tata cara pengambilan dan pengolahan data, serta langkah pemberian prediksi dan rekomendasi perbaikan. Langkah selanjutnya adalah melakukan pengamatan terhadap lokasi penelitian dan pengambilan data primer. Data primer dari lokasi penelitian dan data sekunder diolah untuk didapatkan analisis kasus, yang selanjutnya digunakan untuk memberikan evaluasi kinerja simpang bersinyal Jalan Pahlawan - Raden Saleh Sarif Bustaman. Bagan alir pelaksanaan penelitian disajikan pada Gambar 1.

Pengambilan data primer dilakukan pada jam puncak yang telah ditentukan, yaitu sebanyak tiga periode, yaitu pada pagi hari mulai pukul pukul 06.30 - 08.30, di siang hari mulai pukul 12.20 - 14.20 dan di sore hari mulai pukul 17.30 - 19.30. Jam puncak adalah arus lalu lintas tertinggi dalam satu jam dalam satu hari. Pengambilan data di lokasi penelitian dilakukan selama 2 hari, yaitu pada hari Sabtu dan Rabu, sehingga didapatkan data kondisi lalu lintas simpang pada hari libur dan hari kerja. Data sekunder akan dikumpulkan dari website resmi pemerintah, sehingga didapatkan data yang valid.

Pengolahan data primer dan sekunder dilakukan berdasarkan persamaan pada MKJI 1997 yang dimasukan kedalam Microsoft Excel. Pengolahan data pada analisa simpang bersinyal berdasarkan MKJI 1997 (Dirbinkot 1997) dilakukan dengan rincian:

a. Geometri

Perhitungan geometri dikerjakan secara terpisah untuk setiap pendekat, 
setiap lengan simpang dapat terdiri dari satu atau lebih pendekat. Lengan simpang dengan lebih dari satu pendekat dipisahkan menjadi dua atau lebih subpendekat untuk memisahkan gerak belok dan lurus. Penetapan pendekat dan subpendekat lebar efektif dilakukan dengan mempertimbangkan denah dari bagian masuk dan keluar suatu simpang dan distribusi akibat gerakan-gerakan membelok.

b. Arus Lalu Lintas

Perhitungan arus lalu lintas dilakukan per satuan jam untuk satu atau lebih periode, misalnya didasarkan pada kondisi arus lalu lintas rencana jam puncak pagi, siang dan sore. Arus lalu lintas (Q) untuk setiap gerakan belok kiri (QLT), lurus (QST) dan belok kanan (QRT) harus dikonversikan dari kendaraan per-jam menjadi satuan mobil penumpang (SMP) per-jam dengan menggunakan ekivalen kendaraan penumpang (EMP) untuk masing-masing pendekat terlindung dan terlawan. Nilai EMP yang digunakan berdasarkan MKJI 1997 (Dirbinkot 1997) disajikan pada Tabel 1. Persamaan yang digunakan dalam perhitungan arus lalu lintas adalah seperti pada persamaan (1).

$Q=Q_{L V}+\left(Q_{H V} x e m p_{H V}\right)+\left(Q_{M C} x e m p_{M C}\right)$

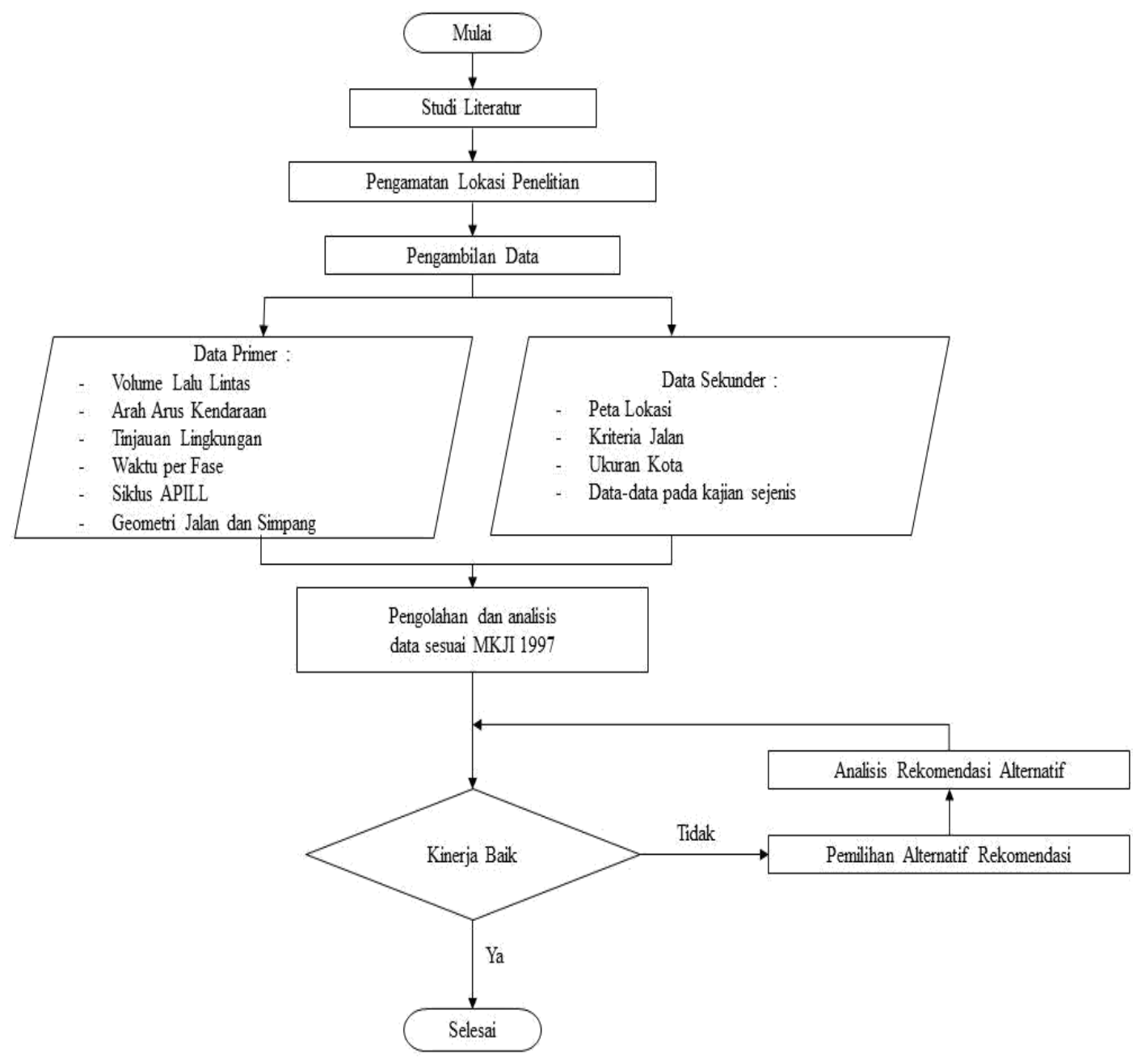

Gambar 1 Bagan Alir Penelitian 
Tabel 1 Nilai EMP untuk Pendekat Terlindung dan Terlawan

\begin{tabular}{lcc}
\hline \multirow{2}{*}{ Jenis Kendaraan } & \multicolumn{2}{c}{ EMP untuk Tipe Pendekat : } \\
\cline { 2 - 3 } & Terlindung & Terlawan \\
\hline Kendaraan Ringan (LV) & 1.0 & 1.0 \\
Kendaraan Berat (HV) & 1.3 & 1.3 \\
Sepeda Motor (MC) & 0.2 & 0.4 \\
\hline
\end{tabular}

c. Model Dasar

Perhitungan kapasitas lengan pendekat bergantung pada rasio waktu hijau dan arus jenuh (Rahayu et al. 2009). Perhitungan pendekat simpang bersinyal dilakukan melalui persamaan (2).

$C=S \times g / c$

Keterangan :

$\mathrm{C}=$ kapasitas (smp/jam)

$\mathrm{S}=$ arus jenuh, yaitu arus berangkat ratarata dari antrian dalam pendekat selama sinyal hijau (smp/jam hijau)

$\mathrm{g}=$ waktu hijau (detik)

$\mathrm{c}=$ waktu siklus, yaitu selang waktu untuk urutan perubahan sinyal yang lengkap (yaitu antara dua awal hijau yang berurutan pada fase yang sama)

Arus jenuh (S) dapat dinyatakan sebagai hasil perkalian dari arus jenuh dasar $\left(\mathrm{S}_{0}\right)$. Arus jenuh dasar adalah arus jenuh pada keadaan standar dengan faktor penyesuaian $(\mathrm{F})$ untuk penyimpangan dari kondisi sebenarnya dari suatu kumpulan kondisi-kondisi (ideal) yang telah diterapkan sebelumnya. Perhitungan arus jenuh dilakukan menggunakan persamaan (3).

$S=S_{0} \times F_{1} \times F_{2} \times F_{3} \times F_{n}$

Pada MKJI 1997 (Dirbinkot 1997), nilai arus jenuh dasar untuk pendekat terlindung ditentukan sebagai fungsi dari lebar efektif pendekat (Wc). Perhitungan arus jenuh dasar dapat dilakukan melalui persamaan (4).

$S_{0}=600 \times W_{C}$

\section{d. Penentuan Waktu Sinyal}

Penentuan waktu sinyal untuk keadaan dengan kendali waktu tetap dilakukan berdasarkan metoda Webster 1966 ( dalam Dirbinkot 1997) untuk mengurangi tundaan total pada suatu simpang. Tahapan dalam penentuan waktu sinyal ini terdiri dari perhitungan waktu siklus (c) dan waktu hijau pada setiap fase $\left(g_{i}\right)$. Perhitungan waktu siklus dapat dilakukan melalui persamaan (5) dan perhitungan waktu hijau malalui persamaan (6).

$c=(1.5 \times L T I+5) /\left(1-\Sigma F R_{\text {crit }}\right)$

$g_{i}=(c-L T I) x F R_{\text {crit }} / L\left(F R_{\text {crit }}\right)$

e. Kapasitas dan Derajat Kejenuhan

Nilai kapasitas pendekat diperoleh melalui perhitungan pada persamaan (1), sehingga untuk perhitungan derajat kejenuhan dapat dilakukan melalui persamaan (7). Besarnya nilai derajat kejenuhan ditentukan oleh faktor konstanta arus jenuh serta faktor koreksi dari hambatan samping. Derajat kejenuhan berpengaruh pada panjang antrian (Rahayu et al. 2009). Kinerja simpang APILL yang baik menurut pedoman kapasitas jalan Indonesia (PKJI) 
2015, adalah simpang dengan nilai derajat kejenuhan (DS) $\leq 0.85$ (Pusjatan 2015).

$$
D S=\frac{g}{c}=(Q x C) /(S x g)
$$

\section{f. Perilaku Lalu Lintas (Kualitas Lalu Lintas)}

Kualitas lalu lintas ini dapat dinilai dari panjang antrian, angka henti, rasio kendaraan terhenti dan tundaan. Jumlah rata-rata antrian (smp) pada awal sinyal hijau (NQ) dapat dihitung melalui persamaan (8).

$N Q=N Q_{1}+N Q_{2}$

Keterangan :

$\mathrm{NQ}_{1}=$ jumlah smp yang tersisa dari fase hijau sebelumnya

$\mathrm{NQ}_{2}=$ jumlah smp yang datang selama fase merah

Nilai $\mathrm{NQ}_{1}$ dan $\mathrm{NQ}_{2}$ dapat dihitung secara berturut-turut melalui persamaan (9) dan (10). Persamaan (9) digunakan bila $\mathrm{DS}>0.5$; untuk nilai $\mathrm{DS}<0.5, \mathrm{NQ}_{1}=$ 0 .

$$
\begin{aligned}
& N Q_{1}=0.25 \times C \times\left[(D S-1)+\sqrt{(D S-1)^{2}+\frac{8 \times(D S-0.5)}{c}}\right] \\
& N Q_{2}=c \times \frac{1-G R}{1-G R \times D S} \times \frac{Q}{3600}
\end{aligned}
$$

Keterangan :

$\mathrm{GR}=$ rasio hijau

Nilai panjang antrian dapat dihitung melalui persamaan (11). Panjang antrian adalah panjang kendaraan yang mengantri pada lengan pendekat sebelum melewati persimpangan (Warsiti et al. 2016).

$Q L=N Q_{M A X} \times \frac{20}{W_{M A S U K}}$

Keterangan :

$\mathrm{Q} \quad=$ panjang antrian $(\mathrm{m})$

$\mathrm{W}_{\text {MASUK }}=$ lebar masuk

20 = luas rata-rata yang dipergunakan per smp $\left(20 \mathrm{~m}^{2}\right)$
Perhitungan angka henti (NS) yaitu jumlah berhenti rata-rata per-kendaraan sebelum melewati suatu simpang dapat dihitung melalui persamaan (12). Nilai NS digunakan untuk perhitungan nilai rasio kendaraan terhenti (Psv), yaitu rasio kendaraan yang harus berhenti akibat sinyal merah sebelum melewati suatu simpang. Nilai Psv diperoleh berdasarkan nilai minimum dari NS.

$N S=0.9 \times \frac{N Q}{Q x C} \times 3600$

Tundaan dapat terjadi karena dua hal yaitu tundaan lalu lintas (DT) dan tundaan geometri (DG). Tundaan lalu lintas terjadi karena interaksi lalu lintas dengan gerakan lainnya pada suatu simpang, sementara tundaan geometri terjadi karena perlambatan dan percepatan saat membelok pada suatu simpang atau terhenti karena lampu merah. Tundaan rata-rata untuk suatu pendekat dapat dirumuskan seperti pada persamaan (13). Nilai DT dan DG diperoleh melalui perhitungan dengan persamaan (14) dan (15) (Dirbinkot 1997).

$D_{j}=D T_{j}+D G_{j}$

Keterangan :

$\mathrm{D}_{\mathrm{j}}=$ tundaan rata-rata untuk pendekat $\mathrm{j}$ (det/smp)

$\mathrm{DT}_{\mathrm{j}}=$ tundaan lalu lintas rata-rata untuk pendekat $\mathrm{j}(\operatorname{det} / \mathrm{smp})$

$\mathrm{DG}_{\mathrm{j}}=$ tundaan geometri rata-rata lalu lintas untuk pendekat $\mathrm{j}$ (det/smp)

$D T_{j}=c \times \frac{0,5 \times(1-G R)^{2}}{(1-G R \times D S)}+\frac{N Q_{1} \times 3600}{c}$

$D G_{j}=\left(1-P_{S V}\right) x P_{T} x 6+\left(P_{S V} x 4\right)$ 


\section{HASIL DAN PEMBAHASAN}

\section{Profil Simpang}

Simpang Jalan Pahlawan - Raden Saleh Sarif Bustaman merupakan simpang bersinyal tipe 322 yang dilewati kendaraan dari Jalan Pahlawan (arah Bogor Nirwana Residence), Jalan Raden Saleh Bustaman (arah Bogor Trade Mall) dan Jalan Empang. Simpang tipe 322 merupakan simpang 3 dengan pengaturan belok kiri langsung yang melayani Kota Bogor. Persimpangan yang diteliti memiliki pendekat terlindung, dimana ketiga arus kendaraan dipisahkan melalui APILL (Alat Pemberi Isyarat Lalu Lintas) sehingga tidak terjadi konflik antar kendaraan dari arah berlawanan. Ketiga jalan tersebut secara berturut-turut selanjutnya diidentifikasi sebagai pendekat Timur, Utara, dan Barat. Karateristik dari masing-masing pendekat tersebut dapat dilihat pada Tabel 2.

Pendekat Timur, Utara, dan Barat memiliki tipe geometri jalan 4/2 D (4 lajur pada 2 arah yang dipisahkan oleh median jalan). Lebar jalan untuk pendekat Timur kedua arah sebesar $13.2 \mathrm{~m}$. Lebar jalan untuk pendekat Utara kedua arah sebesar $13.4 \mathrm{~m}$ dengan lebar median jalan sebesar $\pm 0.4 \mathrm{~m}$. Lebar jalan untuk pendekat Barat kedua arah sebesar $11 \mathrm{~m}$. Hambatan samping yang terjadi dari aktivitas di sepanjang jalan ini diklasifikasikan tinggi akibat terdapat beberapa aktivitas di pinggir jalan, seperti adanya angkutan kota yang berhenti ataupun menaikkan dan menurunkan penumpang serta disepanjang jalan ini merupakan area komersial sehingga hambatan samping diklasifikasikan tinggi.

Jam puncak lalu lintas pada simpang Jalan Pahlawan - Raden Saleh Sarif Bustaman terjadi pada hari Sabtu, 17 Maret 2018 antara pukul 17.20 - 19.20 dengan volume lalu lintas sebesar 5087 SMP/jam. Jam puncak lalu lintas pada Hari Rabu, 14 Maret 2018 terjadi pada pukul 06.30 - 08.30 dengan volume sebesar $4670 \mathrm{SMP} / \mathrm{jam}$. Jam puncak lalu lintas pada simpang selanjutnya digunakan untuk analisis kinerja simpang, beserta tingkat pelayanan simpang berdasarkan PM No. 96 tahun 2015 tentang Pedoman Pelaksanaan Kegiatan Manajemen dan Rekayasa Lalu Lintas dalan Kemenhub 2015.

Tabel 3 merupakan data arus lalu lintas jam sibuk untuk masing-masing pendekat karakteristik volume lalu lintas pada hari kerja berbeda dengan akhir pekan, terlihat dari jumlah kendaraan yang berbeda, dimana pada akhir pekan terdapat kendaraan sebanyak 11653 kendaraan/jam, sedangkan pada hari kerja terdapat kendaraan sebanyak 11145 kendaraan/jam. Data hasil pengamatan lalu diubah kedalam SMP (Satuan Mobil Penumpang) berdasarkan jumlah kendaraan/jam, sehingga didapat satuan arus lalu lintas yang dapat digunakan untuk seluruh jenis kendaraan. Faktor pengubah EMP menjadi SMP dapat dilihat pada Tabel 4.

Tabel 2 Identifikasi Simpang Jalan Pahlawan - Raden Saleh Sarif Bustaman

\begin{tabular}{cccccc}
$\begin{array}{c}\text { Kode } \\
\text { Pendekat }\end{array}$ & $\begin{array}{c}\text { Lebar Efektif } \\
\text { Pendekat } \\
(\mathrm{m})\end{array}$ & $\begin{array}{c}\text { Lebar Masuk } \\
(\mathrm{m})\end{array}$ & Tipe Jalan & $\begin{array}{c}\text { Median } \\
(\mathrm{m})\end{array}$ & $\begin{array}{c}\text { Hambatan } \\
\text { Samping }\end{array}$ \\
\hline Timur & 6.4 & 6.4 & $4 / 2 \mathrm{D}$ & 0.4 & Tinggi \\
Utara & 6.3 & 6.7 & $4 / 2 \mathrm{D}$ & 0.4 & Tinggi \\
Barat & 5.5 & 5.5 & $4 / 2 \mathrm{D}$ & 0.4 & Tinggi \\
\hline
\end{tabular}


Tabel 3 Arus Lalu Lintas Puncak pada Jam Sibuk

\begin{tabular}{|c|c|c|c|c|c|}
\hline \multirow{2}{*}{ Pendekat } & \multirow{2}{*}{ Kode } & \multicolumn{3}{|c|}{$\begin{array}{c}\text { Waktu } \\
17.20-19.20\end{array}$} & \multirow[t]{2}{*}{ Total } \\
\hline & & $\begin{array}{c}\text { LTOR } \\
\text { (kend/jam) }\end{array}$ & $\begin{array}{c}\mathrm{ST} \\
\text { (kend/jam) }\end{array}$ & $\begin{array}{c}\mathrm{RT} \\
\text { (kend/jam) }\end{array}$ & \\
\hline \multirow{4}{*}{$\begin{array}{c}\text { Fase I Timur } \\
\text { Jalan } \\
\text { Pahlawan }\end{array}$} & Kendaraan Ringan & - & 192 & 574 & \multirow{4}{*}{3646} \\
\hline & Kendaraan Berat & - & 6 & 3 & \\
\hline & Sepeda Motor & - & 543 & 2326 & \\
\hline & Tidak Bermotor & - & 1 & 1 & \\
\hline \multirow{4}{*}{$\begin{array}{c}\text { Fase II Barat } \\
\text { Jalan } \\
\text { Empang }\end{array}$} & Kendaraan Ringan & 299 & 340 & - & \multirow{4}{*}{5313} \\
\hline & Kendaraan Berat & 5 & 7 & - & \\
\hline & Sepeda Motor & 2831 & 1831 & - & \\
\hline & Tidak Bermotor & 0 & 0 & - & \\
\hline \multirow{4}{*}{$\begin{array}{c}\text { Fase III } \\
\text { Utara Jalan } \\
\text { Raden Saleh } \\
\text { Sarif } \\
\text { Bustaman }\end{array}$} & Kendaraan Ringan & 399 & - & 277 & \multirow{4}{*}{2694} \\
\hline & Kendaraan Berat & 5 & - & 10 & \\
\hline & Sepeda Motor & 909 & - & 1094 & \\
\hline & Tidak Bermotor & 0 & - & 0 & \\
\hline
\end{tabular}

Tabel 4 Variabel Pengubah Menjadi SMP

\begin{tabular}{lcc}
\hline Jenis Kendaraan & Terlindung & Terlawan \\
\hline Kendaraan Ringan (LV) & 1 & 1 \\
Kendaraan Berat (HV) & 1.3 & 1.3 \\
Sepeda Motor (MC) & 0.2 & 0.4 \\
\hline
\end{tabular}

Selanjutnya dari data tersebut Satuan mobil penumpang arus lalu lintas diubah kedalam SMP sehingga didapat puncak pada jam sibuk untuk masingsatuan arus lalu lintas yang dapat masing pendekat dapat dilihat pada Tabel digunakan untuk seluruh jenis kendaraan. 5 .

Tabel 5 Satuan Mobil Penumpang Arus Lalu Lintas Puncak pada Jam Sibuk

\begin{tabular}{|c|c|c|c|c|c|}
\hline \multirow{2}{*}{ Pendekat } & \multirow{2}{*}{ Kode } & \multicolumn{3}{|c|}{$\begin{array}{c}\text { Waktu } \\
17.20-19.20\end{array}$} & \multirow[t]{2}{*}{ Total } \\
\hline & & $\begin{array}{c}\text { LTOR } \\
\text { (smp/jam) }\end{array}$ & $\begin{array}{c}\mathrm{ST} \\
\text { (smp/jam) }\end{array}$ & $\begin{array}{c}\mathrm{RT} \\
\text { (smp/jam) }\end{array}$ & \\
\hline \multirow{4}{*}{$\begin{array}{c}\text { Fase I Timur } \\
\text { Jalan } \\
\text { Pahlawan }\end{array}$} & Kendaraan Ringan & - & 192 & 574 & \multirow{4}{*}{1819} \\
\hline & Kendaraan Berat & - & 7.8 & 3.9 & \\
\hline & Sepeda Motor & - & 108.6 & 930.4 & \\
\hline & Tidak Bermotor & - & 1 & 1 & \\
\hline \multirow{4}{*}{$\begin{array}{c}\text { Fase II Barat } \\
\text { Jalan } \\
\text { Empang }\end{array}$} & Kendaraan Ringan & 299 & 340 & - & \multirow{4}{*}{1953} \\
\hline & Kendaraan Berat & 6.5 & 9.1 & - & \\
\hline & Sepeda Motor & 566.2 & 732.4 & - & \\
\hline & Tidak Bermotor & 0 & 0 & - & \\
\hline \multirow{4}{*}{$\begin{array}{c}\text { Fase III } \\
\text { Utara Jalan } \\
\text { Raden Saleh } \\
\text { Sarif } \\
\text { Bustaman }\end{array}$} & Kendaraan Ringan & 399 & - & 277 & \multirow{4}{*}{1315} \\
\hline & Kendaraan Berat & 6.5 & - & 13 & \\
\hline & Sepeda Motor & 181.8 & - & 437.6 & \\
\hline & Tidak Bermotor & 0 & - & 0 & \\
\hline
\end{tabular}


Kapasitas dan Derajat Kejenuhan Simpang Perhitungan kapasitas simpang dilakukan menggunakan jam puncak lalu lintas pada simpang, yaitu pada hari Sabtu, 17 Maret 2018. Menurut Dirbinkot 1997 dalam MKJI, kapasitas simpang merupakan arus lalu lintas maksimum yang dapat dipertahankan oleh simpang, yang sangat bergantung dari ukuran jalan pendekat pada simpang. Pendekat dengan ukuran jalan kecil dapat meningkatkan derajat kejenuhan simpang dan menurunkan tingkat pelayanan simpang. Derajat kejenuhan simpang pada kondisi eksisting sudah mendekati kinerja yang jenuh, dengan hasil perhitungan pada simpang pendekat timur yang berada diangka 0.75. Perhitungan kapasitas dan derajat kejenuhan dapat dilihat pada Tabel 6. Perhitungan kapasitas simpang dipengaruhi oleh arus jenuh, waktu hujau dan waktu siklus. Arus jenuh memiliki beberapa faktor seperti kapasitas dasar, faktor ukuran kota, hambatan samping, kelandaian, parkir, koreksi belok kiri, dan koreksi belok kanan. Dapat dilihat pada tabel 6 kapasitas simpang terendah ada pada pendekat Timur dengan nilai kapasitas 2424 SMP/jam. Perhitungan arus jenuh dapat dilihat pada tabel 7 .

Dari tabel 7 didapatkan nilai ukuran kota 1.05 karena pada penelitian ini dilakukan di Kota Bogor dengan kategori kota sangat besar yang memiliki jumlah penduduk diatas 3 juta. Nilai hambatan samping didapat 0.93 karena pada simpang Jalan Pahlawan - Raden Saleh Sarif Bustaman merupakan lingkungan jalan komersil yang hambatan sampingnya tergolong tinggi.

Tabel 6 Perhitungan Kapasitas dan Derajat Kejenuhan

\begin{tabular}{cccc}
\hline & Arus Lalu Lintas & Kapasitas & Derajat \\
Kode Pendekat & $($ smp/jam $)$ & (smp/jam) & Kejenuhan \\
& & & 0,75 \\
\hline Timur & 1819 & 2424 & 0,63 \\
Utara & 1953 & 3108 & 0,49 \\
Barat & 1315 & 2674 & \\
\hline
\end{tabular}

Tabel 7 Perhitungan Arus Jenuh

\begin{tabular}{cccc}
\hline & \multicolumn{3}{c}{ Kode Pendekat } \\
\cline { 2 - 4 } Faktor & Timur & Utara & Barat \\
& & & 3300 \\
\hline So & 3840 & 3780 & 1.05 \\
FCS & 1.05 & 1.05 & 0.93 \\
FSF & 0.93 & 0.93 & 1 \\
FG & 1 & 1 & 1 \\
FP & 1 & 1 & 0.96 \\
FRT & 0.82 & 0.89 & 1.03 \\
FLT & 0.94 & 1.12 & \\
\hline
\end{tabular}




\begin{tabular}{cccc}
\hline $\mathrm{S}(\mathrm{smp} / \mathrm{jam})$ & 2871 & 3682 & 3167 \\
\hline
\end{tabular}

Tabel 8 Perhitungan Hasil Nilai Tundaan

\begin{tabular}{ccccc}
\hline $\begin{array}{c}\text { Kode } \\
\text { Pendekat }\end{array}$ & $\begin{array}{c}\text { Arus Lalu } \\
\text { Lintas } \\
\text { (SMP/jam) }\end{array}$ & $\begin{array}{c}\text { DT } \\
\text { (detik/SMP) }\end{array}$ & $\begin{array}{c}\text { DG } \\
\text { (detik/SMP) }\end{array}$ & $\begin{array}{c}\text { D } \\
\text { (det/SMP) }\end{array}$ \\
\hline Timur & 1819 & 67 & 4.47 & 71 \\
Utara & 1953 & 32 & 4.87 & 37 \\
Barat & 1315 & 15 & 6.27 & 22 \\
\hline
\end{tabular}

\section{Tingkat Pelayanan Simpang}

Tingkat pelayanan simpang merupakan ukuran kuantitatif dan kualitatif yang menggambarkan kondisi operasional lalu lintas pada suatu simpang (Kemenhub 2015). Tingkat pelayanan simpang (Level of Service) dinyatakan dalam huruf mutu berdasarkan waktu tundaan (delay) yang dialami tiap kendaraan. Tundaan (D) merupakan total waktu hambatan rata-rata yang dialami oleh kendaraan sewaktu melewati suatu simpang. Nilai tundaan simpang pada kondisi eksisting dapat dilihat pada Tabel 8.

Nilai tundaan tertinggi terdapat pada pendekat timur yaitu dengan nilai tundaan $71 \mathrm{detik} / \mathrm{smp}$. Nilai tundaan yang tinggi sangat mempengaruhi level of service (LoS). Selain itu, LoS dipengaruhi oleh besar arus lalu lintas, lebar efektif jalan, dan waktu hijau pada siklus APILL. Nilai tundaan lalu lintas pada kondisi eksisting didapatkan 45 detik/SMP yaitu pada tingkat pelayanan $\mathrm{E}$ karena nilai tundaan berada diantara 25 sampai 40 detik/kendaraan. Nilai tundaan 45 detik/SMP terlalu tinggi sehingga diperlukan pemberian perlakuan yang digambarkan dalam beberapa skenario.

Perbaikan kondisi eksisting simpang dilakukan dengan memberikan dua skenario alternatif yang akan dianalisis dalam upaya peningkatan pelayanan simpang Jalan Pahlawan Raden Saleh Sarif Bustaman. Skenario I adalah situasi dengan penambahan waktu hijau pada masing-masing APILL dengan asumsi arus lalu lintas sama dengan kondisi eksisting. Skenario II adalah kondisi perbaikan dari Skenario I dengan penambahan satu lajur atau diberikan pelebaran jalan pada masing-masing pendekat dengan waktu siklus APILL yang sama dengan kondisi Skenario I hingga didapat nilai level of service (LoS) $B$ dengan nilai tundaan rata-rata simpang 9 detik/SMP. Perbandingan kondisi simpang eksisting dan setelah adanya skenario dapat dilihat pada Tabel 9.

Pada kondisi Eksisting siklus APILL pada simpang Jalan Pahlawan Raden Saleh Sarif Bustaman dapat dilihat pada Gambar 2. Pada Fase I dari arah Timur memiliki 25 detik waktu hijau, yang diikuti dengan 2 detik waktu kuning, dan 50 detik waktu merah. Fase II dari arah Barat memiliki 15 detik waktu hijau, yang diikuti dengan 2 detik waktu kuning, 6 detik waktu merah semua, dan 27 detik waktu merah. Fase III dari arah Utara memiliki 25 detik waktu hijau, 2 detik waktu kuning, dan 50 detik waktu merah.

Berdasarkan waktu hijau pada skenario alternatif terbaik, dihitung siklus APILL baru dengan penambahan waktu merah semua hasil perhitungan dan waktu kuning. Siklus baru pada simpang Jalan Pahlawan - Raden Saleh Sarif Bustaman pada Gambar 3. Pemberian waktu merah semua setelah Fase II dilakukan untuk mencegah pertemuan antar kendaraan dari fase berbeda pada titik konflik simpang, sehingga dapat mencegah terjadinya kecelakaan pada simpang. 
Tabel 9 Perbandingan Kondisi Eksisting, Skenario I dan II

\begin{tabular}{|c|c|c|c|c|}
\hline Pendekat & Kondisi & Timur & Utara & Barat \\
\hline \multirow{3}{*}{$\begin{array}{l}\text { Arus Lalu Lintas } \\
\text { (SMP/Jam) }\end{array}$} & Eksisting & & & \\
\hline & Skenario I & 1819 & 1953 & 1315 \\
\hline & Skenario II & & & \\
\hline \multirow{3}{*}{$\begin{array}{l}\text { Lebar Efektif } \\
\text { (m) }\end{array}$} & Eksisting & 6.4 & 6.3 & 5.5 \\
\hline & Skenario I & 6.4 & 6.3 & 5.5 \\
\hline & Skenario II & 9.4 & 9.3 & 8.5 \\
\hline \multirow{3}{*}{$\begin{array}{l}\text { Cycle Time } \\
\text { (detik) }\end{array}$} & Eksisting & & 77 & \\
\hline & Skenario I & & 137 & \\
\hline & Skenario II & & 137 & \\
\hline \multirow{3}{*}{$\begin{array}{l}\text { Waktu Hijau } \\
\text { (detik) }\end{array}$} & Eksisting & 25 & 15 & 25 \\
\hline & Skenario I & 45 & 25 & 55 \\
\hline & Skenario II & 45 & 25 & 55 \\
\hline \multirow{3}{*}{$\begin{array}{l}\text { Kapasitas } \\
\text { (SMP/Jam) }\end{array}$} & Eksisting & 2424 & 3108 & 2674 \\
\hline & Skenario I & 2676 & 3432 & 2952 \\
\hline & Skenario III & 3931 & 5066 & 4562 \\
\hline \multirow{3}{*}{$\begin{array}{c}\text { Derajat } \\
\text { Kejenuhan }(Q / C)\end{array}$} & Eksisting & 0.75 & 0.63 & 0.49 \\
\hline & Skenario I & 0.68 & 0.57 & 0.45 \\
\hline & Skenario II & 0.46 & 0.39 & 0.29 \\
\hline \multirow{3}{*}{$\begin{array}{c}\text { Tundaan Simpang } \\
\text { Rata-rata } \\
\text { (det/SMP) }\end{array}$} & Eksisting & & 45 & \\
\hline & Skenario I & & 18 & \\
\hline & Skenario II & & 9 & \\
\hline
\end{tabular}

\begin{tabular}{|l|r|r|r|r|r|r|r|r|}
\hline Fase I (Timur) & 25 & 2 & & & 50 & \multicolumn{2}{|c|}{} \\
\hline Fase II (Barat) & 27 & & 15 & 2 & 6 & & 27 \\
\hline Fase III (Utara) & & & 50 & & & 25 & 2 \\
\hline
\end{tabular}

Gambar 2 Diagram Siklus APILL Eksisting

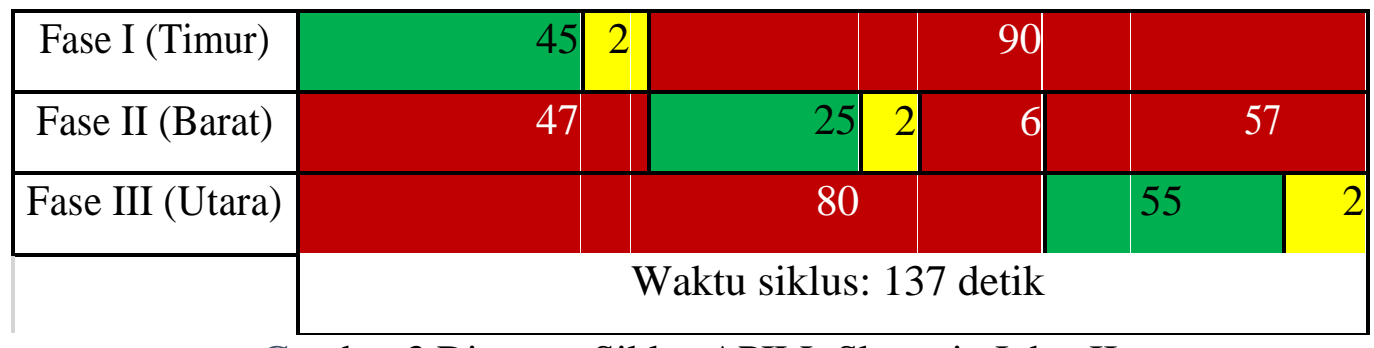

Gambar 3 Diagram Siklus APILL Skenario I dan II 
Perhitungan pada skenario I dan II dilakukan dengan mengubah waktu hijau pada siklus APILL hingga mencapai tingkat pelayanan yang terbaik. Pada skenario I, simpang Jalan Pahlawan Raden Saleh Sarif Bustaman tidak mengalami pelebaran jalan. Waktu hijau yang digunakan pada skenario I yaitu sebesar 125 detik, namun tundaan simpang rata-rata masih tinggi yaitu 18 detik/SMP dan berada pada tingkat pelayanan C. Operasional pada tingkat pelayanan $\mathrm{C}$ berada pada selang arus stabil, tetapi ditandai dengan awal operasi pengguna individu yang dipengaruhi oleh interaksi lain dalam arus lalu lintas.

Nilai tundaan simpang rata-rata pada skenario II didapatkan sebesar 9 detik/SMP, sehingga didapatkan simpang dengan tingkat pelayanan B. Operasional pada tingkat pelayanan B berada dalam selang arus stabil dengan volume lalu lintas sedang dan kecepatan mulai dibatasi oleh kondisi lalu lintas. Tingkat pelayanan simpang pada skenario II B dapat dinyatakan sebagai kondisi alternatif terbaik bagi simpang Jalan Pahlawan Raden Saleh Sarif Bustaman. Dimensi simpang pada skenario II dapat dilihat pada Gambar 4.

\section{Yellow Box Junction}

Penambahan yellow box junction pada simpang bertujuan untuk mencegah timbulnya antrian kendaraan pada simpang. Yellow Box Junction adalah marka jalan berwarna kuning yang berada di perkerasan jalan yang berfungsi mencegah antrian pada simpang. Adanya antrian kendaraan pada simpang berpotensi menyebabkan terjadinya antrian yang memanjang pada jalan pendekat, terutama bagi kendaraan yang memiliki lintasan yang saling berpotongan seperti pada Gambar 4. Kendaraan yang sedang memiliki waktu hijau dilarang melalui simpang apabila masih terdapat kendaraan dari waktu hijau pendekat sebelumnya yang masih terhenti/ mengantri di simpang tersebut (Tjahjani dan Hutapea 2013). Pengemudi kendaraan yang akan melalui simpang dengan yellow box junction diharuskan juga memastikan ada ruang henti bagi kendaraan setelah lolos dari simpang, sehingga tidak akan timbul antrian pada simpang. Kendaraan yang memaksa masuk kedalam yellow box junction saat ada antrian pendekat dari waktu hijau sebelumnya dan kendaraan yang terhenti pada yellow box junction akan dikenakan sanksi melanggar instruksi marka jalan dan APILL, sesuai Undang-Undang Nomor 22 Tahun 2009 tentang Lalu Lintas dan Angkutan Jalan Pasal 287 ayat (2) dengan pidana kurungan maksimal dua bulan atau denda paling banyak Rp 500,000,-. Efektivitas penerapan simpang dengan yellow box junction memerlukan adanya petugas sosialisasi khusus serta pengawasan menggunakan closed circuit television (CCTV) untuk menanggapi kendaraan yang melanggar. Kondisi simpang pada skenario II dengan penambahan yellow box junction dapat dilihat pada Gambar 5. Penggambaran yellow box junction pada Gambar 5 telah dilakukan sesuai dengan kaidah pemberian marka dan yellow box junction tidak diberlakukan bagi pendekat yang mengalami gerakan lurus jalan terus dan belok kiri langsung (Department for Transport 2003).

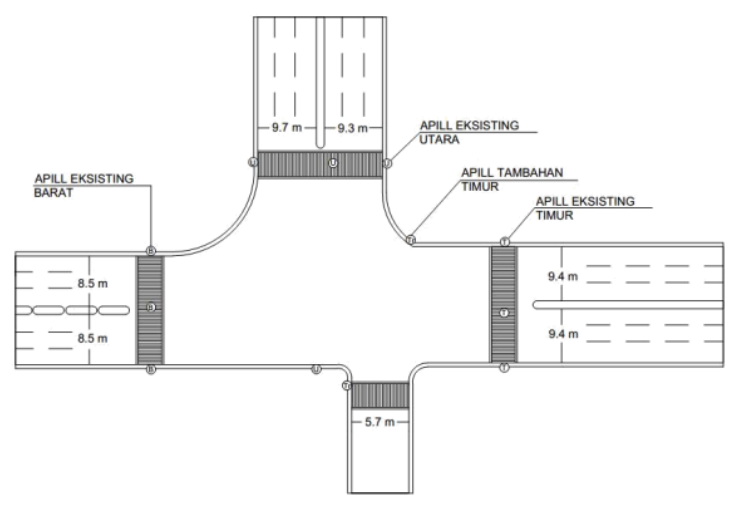

Gambar 4 Dimensi Simpang Skenario II 


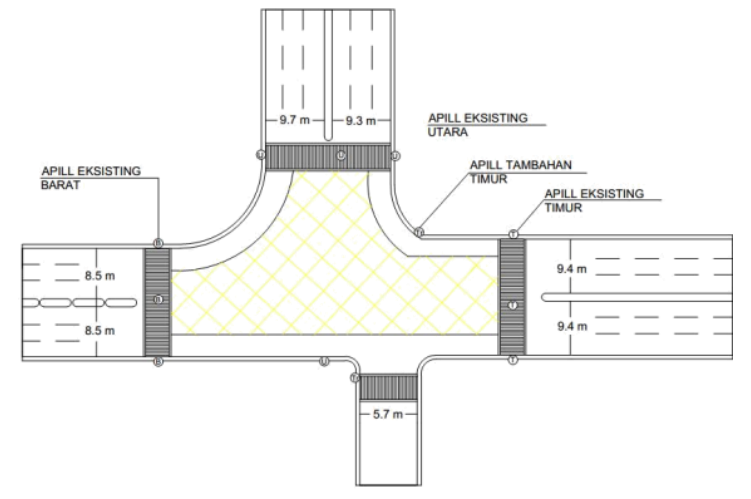

Gambar 5 Simpang Skenario II dengan penambahan yellow box junction

\section{KESIMPULAN}

Berdasarkan penelitian yang telah dilaku disimpulkan bahwa:

1. Hasil analisis kinerja tingkat pelayanan simpang pada simpang Jalan Pahlawan - Raden Saleh Sarif Bustaman didapatkan tidak sesuainya waktu siklus APILL dan ukuran dimensi pendekat yang mengakibatkan tingginya derajat kejenuhan simpang sehingga tingkat pelayanan simpang (level of service) rendah dengan nilai tundaan simpang 45 detik/SMP.

2. Berdasarkan penelitian yang telah dilakukan, diberikan rekomendasi untuk peningkatan kinerja simpang bersinyal Jalan Pahlawan - Raden Saleh Sarif Bustaman dengan 2 skenario yaitu skenario I merupakan situasi dengan penambahan waktu hijau pada masing-masing APILL dengan asumsi arus lalu lintas sama dengan kondisi eksisting, dan skenario II merupakan skenario alternatif terbaik bagi simpang dengan penambahan lajur atau pelebaran jalan sehingga kapasitas simpang meningkat serta tundaan simpang rata-rata sebesar 9 det/SMP. Penerapan Alat Pemberi Isyarat Lalu Lintas (APILL) berupa yellow box junction dapat mencegah antrian pada simpang, sehingga tingkat pelayanan dapat dipertahankan.

\section{SARAN}

Diperlukan adanya penelitian lebih lanjut mengenai kemampuan simpang dengan dimensi tetap untuk melayani persimpangan dengan baik. Kondisi eksisting simpang dilalui kendaraan sebanyak 5087 SMP/jam atau 11653 unit kendaraan/Jam, sehingga telah melampaui kemampuan layanan simpang 3 tipe 322 pada Manual Kapasitas Jalan Indonesia tahun 1997 (2700 SMP/jam). Diperlukan pula studi lanjutan untuk menentukan waktu hijau dan waktu siklus APILL yang sesuai untuk waktu lain selain waktu arus puncak.

Pamencanaan dan pelaksanaan tata kota yang tepat juga diperlukan untuk menjaga daya dukung Kota Bogor seiring meningkatnya jumlah penduduk dan jumlah kendaraan, sehingga akan didapatkan tata kota yang sesuai untuk Kota Bogor dan menjadi kota yang bebas kemacetan.

\section{DAFTAR PUSTAKA}

Department for Transport. 2003. Traffic Signs Manual. London (GB): Office of Public Sector Information

[Dirbinkot] Direktorat Pembinaan Jalan Kota. 1997. Manual Kapasitas Jalan Indonesia (MKJI) 1997. Jakarta (ID): Direktorat Jenderal Bina Marga, Kementerian Pekerjaan Umum

Galfi M. 2012. Studi Simpang Bersinyal pada Simpang 4 (Empat) Sempaja Samarinda. Jurnal Keilmuan dan Aplikasi Teknik Sipil 1(1): 8-29

[Kemenhub] Kementerian Perhubungan. 2015. Pedoman Pelaksanaan Kegiatan Manajemen dan Rekayasa Lalu Lintas. Peraturan Menteri Perhubungan Nomor PM 96 Tahun 2015. Jakarta (ID): Kemenhub 
[Pusjatan] Pusat Penelitian dan Pengembangan Jalan dan Jembatan. 2015. Pedoman Kapasitas Jalan Indonesia (PKJI). Jakarta (ID): Kementerian Pekerjaan Umum

Puspita W A. 2010. Analisis Manajemen Lalu Lintas terhadap Persimpangan Jalan Raya Kletek - Jalan Sawunggaling Akibat Adanya Pusat Perdagangan Agrobisnis (PUSPA AGRO) Jawa Timur [skripsi]. Surabaya (ID): Institut Teknologi Sepuluh Nopember

Rahayu G, Atmaja S, Rosyidi P, Munawar A. 2009. Analisis Arus Jenuh dan Panjang Antrian pada Simpang Bersinyal: Studi Kasus di Jalan Dr. Sutomo-Suryopranoto, Yogyakarta. Jurnal Ilmiah Semesta Teknika 12(1): 99-108

Tjahjani ARI, Hutapea NP. 2013. Analisa Kinerja Marka Yellow Box Junction (Studi Kasus Simpang Jalan Mayjen Sutoyo, Jakarta). Konferensi Nasional Teknik Sipil 7 (Konteks 7) Universitas Sebelas Maret (UNS) 7: 61-68

Warsiti, Sukoyo, Pamungkas G, Herdiansyah MR. 2016. Analisis Kinerja Simpang Bersinyal pada Jalan Kaligarang - Jalan Kelud Raya - Jalan Bendungan Raya. Bangun Rekaprima: Majalah Ilmiah Pengembangan Rekayasa, Sosial, dan Humaniora 2(2): 32-39 
